Review Article

\title{
A detailed approach on multiple myeloma and its treatment
}

\author{
A. Veerendra Sagar*, Ch. Divya, A. Prathyusha, P. Haritha
}

\begin{abstract}
Division of Pharmacology, AU College of Pharmaceutical Sciences, Andhra University, Visakhapatnam, Andhra Pradesh, India
\end{abstract}

Received: 10 October 2013 Accepted: 27 October 2013

\section{*Correspondence to:}

A. Veerendra Sagar,

Email: sagar.spike@yahoo.com

C 2013 Sagar AV et al. This is an open-access article distributed under the terms of the Creative Commons Attribution Non-Commercial License, which permits unrestricted non-commercial use, distribution, and reproduction in any medium, provided the original work is properly cited.

\begin{abstract}
Multiple myeloma is a cancer formed by malignant plasma cells. Normal plasma cells are found in the bone marrow and are an important part of the immune system. The immune system is composed of several types of cells that work together to fight infections and other diseases. Lymphocytes are the main cell type of the immune system. There are 2 major types of lymphocytes: $\mathrm{T}$ cells and $\mathrm{B}$ cells. When $\mathrm{B}$ cells respond to an infection, they mature and change into plasma cells. Plasma cells make the antibodies that help the body attack and kill germs. Lymphocytes can be found in many areas of the body, such as lymph nodes, the bone marrow, the intestines, and the bloodstream. Plasma cells, however, are mainly found in the bone marrow. Bone marrow is the soft tissue inside some hollow bones. In addition to plasma cells, normal bone marrow has cells that make the different normal blood cells. When plasma cells become cancerous and grow out of control they can produce a tumor called a plasmacytoma. These tumors generally develop in a bone, but they are also rarely found in other tissues. If there is only a single plasma cell tumor, it is called an isolated plasmacytoma. When there is more than one plasma cell tumor, it is called 'multiple myeloma'. There are lot of plasma cell abnormalities, but multiple myeloma causes severe bone pain, so here we covered detailed notes on the disease and its treatment strategies.
\end{abstract}

Keywords: Myeloma, Plasma, Tumor, Monoclonal gammopathy, Bone marrow

\section{INTRODUCTION}

Multiple myeloma is a cancer formed by malignant plasma cells. Normal plasma cells are found in the bone marrow and are an important part of the immune system. The immune system is composed of several types of cells that work together to fight infections and other diseases. Lymphocytes are the main cell type of the immune system. There are 2 major types of lymphocytes: $\mathrm{T}$ cells and B cells. ${ }^{1}$ When $\mathrm{B}$ cells respond to an infection, they mature and change into plasma cells. Plasma cells make the antibodies that help the body attack and kill germs. Lymphocytes can be found in many areas of the body, such as lymph nodes, the bone marrow, the intestines, and the bloodstream. Plasma cells, however, are mainly found in the bone marrow. Bone marrow is the soft tissue inside some hollow bones. In multiple myeloma, the overgrowth of plasma cells in the bone marrow can crowd out normal blood-forming cells, leading to low blood counts. People with anemia become pale, weak, and fatigued. Multiple myeloma can also cause the level of platelets in the blood to become low. This can lead to increased bleeding and bruising. Another condition that can develop is a shortage of normal white blood cells. This can lead to problems fighting infections. Myeloma cells also interfere with cells that help keep the bones strong. Bones are constantly being remade to keep them strong. Two major kinds of bone cells normally work together to keep bones healthy and strong. The cells that lay down new bone are called osteoblasts. The cells that break down old bone are called osteoclasts. Myeloma cells make a substance that tells the osteoclasts to speed up dissolving the bone. Since the osteoblasts do not get a signal to put down new bone, old bone is broken down without new bone to replace it. This makes the bones weak and they break easily. Fractured bones are a major problem in people with myeloma. This increase in bone break-down can also raise calcium levels in the blood. Abnormal plasma cells do not protect the body from infections. As mentioned before, normal plasma cells produce antibodies that attack germs. For example, if you developed pneumonia, normal plasma cells would produce antibodies aimed at the specific bacteria that were causing the illness. These antibodies help the body attack and kill the bacteria. In multiple myeloma, the myeloma cells crowd out the normal plasma cells, so that antibodies to fight the infection can't be made. The antibody made by the myeloma cells does not help fight infections. That is because the myeloma cells are just many copies of the 
same plasma cell -all making copies of the same exact (monoclonal) antibody. The antibody made by myeloma cells can harm the kidneys. This can lead to kidney damage and even kidney failure. Having many copies of the same antibody is known as a monoclonal gammopathy. This condition can be found with a blood test. Having a monoclonal gammopathy does not mean you have multiple myeloma. It occurs in other diseases, such as Waldenstrom macroglobulinemia and light chain amyloidosis. Also, some people have a monoclonal gammopathy but it does not cause problems like multiple myeloma does. This condition is called monoclonal gammopathy of undetermined significance (MGUS). Some people with MGUS go on to develop multiple myeloma or other diseases.

\section{RISK FACTORS}

A risk factor is anything that changes a person's chance of getting a disease such as cancer. Different cancers have different risk factors. For example, exposing skin to strong sunlight is a risk factor for skin cancer. Smoking is a risk factor for cancer of the lung and many other cancers. But risk factors don't tell us everything. People who have no risk factors can still get the disease. Also, having a risk factor, or even several, does not mean that a person will get the disease. Scientists have found few risk factors that may affect someone's chance of getting multiple myeloma.

\section{Age}

The risk of multiple myeloma goes up with age. Less than $1 \%$ of cases are diagnosed in people younger than 35 . Most people diagnosed with this cancer are at least 65 years old.

\section{Gender}

Men are slightly more likely to develop multiple myeloma than women.

\section{Race}

Multiple myeloma is more than twice as common among black Americans as white Americans. The reason is not known.

\section{Radiation}

People who were exposed to radiation from an atomic bomb blast had a higher risk of multiple myeloma. Exposure to lower levels of radiation may also increase the risk of multiple myeloma. At most, this accounts for a very small number of cases.

\section{Family history}

Multiple myeloma seems to run in some families. Someone who has a sibling or parent with myeloma is 4 times more likely to get it than would be expected. Still, most patients have no affected relatives, so this accounts for only a small number of cases.

\section{Workplace exposures}

Studies looking at workplace exposures and multiple myeloma risk have found no clear links.

\section{Obesity}

A study by the American Cancer Society has found that being overweight or obese increases a person's risk of developing myeloma.

\section{Other plasma cell diseases}

Many people with other plasma cell diseases will eventually develop multiple myeloma. ${ }^{2}$ They are

\section{Monoclonal gammopathy of undetermined significance (MGUS)}

In monoclonal gammopathy of undetermined significance (MGUS), abnormal plasma cells produce excess amounts of a monoclonal antibody protein. However, these plasma cells do not form an actual tumor or mass and do not cause any of the other problems seen in multiple myeloma. MGUS usually does not affect a person's health. In particular, it doesn't cause weak bones, high calcium levels, kidney problems, or low blood counts. It is most often found because a routine blood test finds a high level of protein in the blood and further testing shows the protein is a monoclonal antibody. In MGUS, the number of plasma cells may be increased, but they still make up less than $10 \%$ of the cells in the bone marrow.

\section{Solitary plasmacytomas}

This is another type of abnormal plasma cell growth. Rather than many tumors in different locations as in multiple myeloma, there is only one tumor, hence the name solitary plasmacytomas. Most often, a solitary plasmacytoma develops in a bone, where it may be called an isolated plasmacytoma of bone. When a plasmacytoma starts in other tissues (such as the lungs or the lining of the sinuses, throat, or other organs), it is called an extramedullary plasmacytoma. Solitary plasmacytomas are most often treated with radiation therapy. Sometimes surgery may be used for a single extramedullary plasmacytoma. As long as no other plasmacytomas are found later on, the patient's outlook is usually excellent. However, since many people with a solitary plasmacytoma will develop multiple myeloma, these people are watched closely for signs of this disease.

\section{SIGNS AND SYMPTOMS}

Bone problems: The myeloma cells make a protein that tells the osteoclasts to speed up dissolving the bone but osteoblasts do not get signal to put down new bone, this 
causes bone to weaken and pain in bones mainly in back, hips and skull. Due to this sometimes bones break only from a minor stress or injury. ${ }^{2}$

Low blood counts: When myeloma cells replace the normal blood-forming marrow cells, shortages of red blood cells, white blood cells, and blood platelets result. These reduced cells counts cause the following conditions:

Red blood cells- Anemia

White blood cells - Leukopenia

Platelets- Thrombocytopenia

High blood Calcium: When myeloma cells dissolve bone, Calcium is released. This leads to high levels of Calcium in blood called Hypocalcaemia. Symptoms include feeling very thirsty, urinating frequently, severe constipation, abdominal pain. If its levels are too high, leads to Coma also.

Nervous system symptoms: In some patients myeloma protein can cause the blood to Thicken, called hyperviscosity. It can slow blood flow to brain and cause confusion, dizziness and stroke like symptoms.

Kidney problems: As there is a higher level of myeloma proteins in blood, it is difficult for kidney to filter thick blood, so that it can be damaged. As the kidney starts to fail, it loses ability to dispose excess salt, fluid and body wastes. This can lead to symptoms like shortage of breath, itching, leg swelling.

Infections: Myeloma patients are much more likely to get infections. Because the body is unable to make proper antibodies and shortage of white blood cells. When someone with myeloma gets an infection, they may be slow to respond to treatment. Pneumonia is a common and serious infection seen in myeloma patients.

\section{DIAGNOSIS}

\section{Laboratory tests}

1) Blood counts

2) Quantitative immunoglobulins

3) Electrophoresis

4) Free light chains

5) Beta-2 Microglobulin

6) Blood chemistry tests

7) Immunohistochemistry

8) Flow cytometry

9) Cytogenetics

10) Fluorescent in situ hybridization

11) Biopsy tests - Bone marrow biopsy

- Fine needle aspiration biopsy

- Core needle biopsy

\section{Imaging studies}
1) Bone X-ray
2) Computed tomography scans
3) Magnetic resonance imaging scans
4) Positron emission tomography scans

\section{TREATMENT}

As it is a cancer, the first choices of drugs are chemotherapy agents, but using them will cause more side effects. So here we have given other treatment options to avoid the following side effects due to chemo drugs.

- Hair loss, Mouth sores

- Loss of appetite

- Nausea and vomiting

- $\quad$ Easy bruising or bleeding

- Fatigue and anemia

The following treatment options are available for Multiple Myeloma:

1. Biophosphates: Myeloma cells can dissolve, weaken and even break bones. Biophosphates help bones stay strong by slowing down this process. ${ }^{3}$ The standard drugs used are Pamidronate and Zoledronic acid. These drugs are given Intravenously (IV). Most patients are treated once a month at first, but they may be able to be treated less often later on if they are doing well. This helps to prevent further bone damage. These drugs have a rare but serious side effect called osteonecrosis of jaw. Patients complain of pain and doctors find that part of jaw bone has died. This can lead to an open sore that does not heal. It can also lead to tooth loss in that area. Doctors are not sure why is this happens and how best to prevent it, but having jaw surgery or having a tooth removed while undergoing Biophosphates therapy may trigger this problem. So these procedures should be avoided while patient is taking Biophosphates. If it occurs, one should stop the therapy.

2. Radiation therapy: This therapy uses focused highenergy X-rays or particles that penetrate the tissues of the body to reach and destroy cancerous cells. Radiation may be used to treat areas of bone damaged by myeloma that have not responded to chemotherapy and are causing pain. ${ }^{32}$ It is also the most common treatment for solitary plasmacytomas. If myeloma severely weakens the vertebral (back) bones, these bones can collapse and put pressure on the spinal cord and spinal nerves. Symptoms include a sudden change in sensation (such as numbness or tingling), sudden weakness of leg muscles, or sudden problems with urination or moving the bowels. This is a medical emergency; patients with these symptoms should call their doctor right away. Prompt treatment with radiation therapy and/or surgery is often needed to prevent paralysis. The type of radiation therapy most often used to treat multiple myeloma or solitary plasmacytoma is called external beam radiation therapy. The radiation is aimed at the cancer from a machine outside the body. Having 
radiation therapy is much like having a diagnostic x-ray except that each treatment lasts longer, and the course of treatment can continue for several weeks.

3. Surgery for myeloma: Although surgery is sometimes used to remove single plasmacytomas, it is rarely used to treat multiple myeloma. When spinal cord compression causes paralysis, severe muscle weakness, or numbness, emergency surgery may be needed. Non-emergency (elective) surgery to attach metal rods or plates can help support weakened bones and may be needed to prevent or treat fractures.

4. Biologic therapy: Biologic therapy uses proteins that are normally found in the body to fight disease, even cancer. Interferon is a hormone-like substance released by some white blood cells and bone marrow cells. When given as a drug, it can slow the growth of myeloma cells. Interferon is sometimes given to patients who have been treated with chemotherapy and the myeloma is in remission. Interferon seems to prolong remission. This drug can cause side effects that include fatigue and other symptoms similar to those from a flu infection. Some patients have trouble tolerating this, but overall the benefits of longer remission and fewer myeloma symptoms may outweigh these side effects. Erythropoietin (Procrit@) and Darbepoietin (Aranesp $囚$ ) are drugs that can help correct anemia from low red blood cells and reduce the need for blood transfusions in some patients who are getting chemotherapy. But the FDA warns that some patients with lymphoid cancers, such as multiple myeloma, had shorter survival or their cancers regrew when they used this type of drug.

5. Stem cell transplant: This has become a standard treatment for younger myeloma patients in otherwise good health. Many centers are using this treatment for older patients as well. Several studies have shown that this treatment increases survival compared to standard chemotherapy. The first step is to treat the myeloma to reduce the amount of cancer in a patient's body. Many different drug combinations can be used. ${ }^{13}$

There are 2 types of stem cell transplant (SCT): autologous and allogeneic.

Autologous stem cell transplant: This type of transplant uses the patient's own blood-forming stem cells. These transplants are fairly safe and have a low risk of serious complications. To collect the patient's stem cells, often the drug cyclophosphamide and a white blood cell stimulating drug are given. Then blood-forming stem cells are removed from the patient's blood by a process called leukapheresis. In this process, blood is removed from the patient or donor, the stem cells are separated by a machine, and then the blood is returned to the patient. In some patients, the stem cells come from their bone marrow. The stem cells are preserved by being frozen while the patient receives high-dose chemo. This chemo destroys almost all the cells in the patient's bone marrow. This includes the blood-forming stem cells as well as plasma cells. After the chemo, the frozen stem cells are given back to the patient. Stem cells are given intravenous like a blood transfusion. They travel to the bone marrow and start to grow and make new blood cells. The chemo can cause many problems. Many patients have high fevers from infections. These are treated with IV antibiotics. Another common problem is mouth sores which can be very painful. Morphine may be given to reduce the pain. The chemo also kills cells in the intestines, which may lead to cramps and diarrhea. Transfusions of red blood cells and platelets are often needed until the bone marrow can again produce enough of these cells. Because this type of transplant is fairly safe with a low risk of serious complications, it can be used in elderly patients. Unfortunately, even high-dose chemo doesn't kill all the myeloma cells, so the myeloma eventually comes back. Some patients are free of myeloma for quite a long time, but they aren't really cured. Some doctors recommend that patients with multiple myeloma have 2 autologous transplants, 6 to 12 months apart. This approach is called tandem transplant. Studies show that this may help patients live longer than a single transplant. The drawback, of course, is that it causes more side effects. Autologous transplants are better than traditional chemo at treating myeloma and can help patients live longer. They are a standard part of myeloma treatment.

Allogenic stem cell transplant: This type of transplant has more risks than autologous transplants, and so it is used much less often to treat multiple myeloma. For this type of transplant, the stem cells come from someone else. The donor is usually a close relative (like a brother or sister). Less often, an unrelated donor is used, someone whose tissue type is closely matched to the patient. Allogeneic transplants are much riskier than autologous transplants, but they may be better at fighting the cancer. That is because transplanted (donor) cells may actually help destroy myeloma cells. This is called a graft $v s$ tumor effect. A patient must be fairly young and healthy to withstand the side effects of this kind of transplant (most myeloma patients are elderly). The transplant also requires a donor matched to the patient. These factors tend to limit the use of this type of transplant in myeloma. ${ }^{14}$

Non myeloablative stem cell transplant: This is a type of allogeneic transplant in which low doses of certain kinds of chemo drugs are used. The chemo doesn't completely wipe out the bone marrow, but it does enough to let the transplanted stem cells take hold. Then it is hoped that the new cells will kill the myeloma cells (graft $v s$ tumor effect). Because lower doses of chemo are used, this type of transplant is sometimes called a mini transplant. The lower chemo doses mean that older patients can have this type of transplant.

6. Plasmapheresis: In this treatment, blood is removed from a vein, the blood cells are separated from the blood plasma (liquid part of the blood) and then the blood cells are returned to the patient. ${ }^{31}$ The discarded plasma has the abnormal antibody protein produced by the myeloma cells. 
It can be replaced with a salt solution and plasma from donors. Plasmapheresis is helpful when certain myeloma proteins build up, thicken the blood, and interfere with circulation (called hyperviscosity). Although plasmapheresis can relieve some symptoms, it does not kill the myeloma cells. Without further treatment, the level of the protein will just build-up again. For that reason, plasmapheresis is often followed by chemotherapy or some other type of drug treatment to kill the cells that make the protein. $^{33}$

\section{SUMMARY}

The first choice of drugs for any type of cancer are chemo drugs. Multiple myeloma being a plasma cell cancer, can be treated effectively by chemo drugs but with utmost side effects, so use of chemo drugs along with the corticosteroids and other immunomodulating drugs is recommended. Other therapies discussed above are nowadays emerging in the treatment of multiple myeloma.

\section{Funding: None \\ Conflict of interest: None declared \\ Ethical approval: Not required}

\section{REFERENCES}

1. American Cancer Society. Cancer Facts and Figures 2012. Atlanta, GA: American Cancer Society; 2012.

2. Anderson KC, Rajkumar SV, Bergsagel PL, Reece DE. Myeloma in, Hematology 2005, American Society of Hematology, pages 340-359. Available at www.asheducationbook.org.

3. Barlogie B, Shaughnessy J, Tricot G, et al. Treatment of multiple myeloma. Blood 2004;103:20-32.

4. Greipp PR, San Miguel J, Durie BG, et al. International staging system for multiple myeloma. J Clin Oncol. 2005 May:3412-3420.

5. Howlader N, Noone AM, Krapcho M, et al (eds). SEER Cancer Statistics Review, 1975- 2008, National Cancer Institute. Bethesda, MD, http://seer.cancer.gov/csr/1975_2008/, based on November 2010 SEER data submission, posted to the SEER web site, 2011.

6. Kyle RA, Rajkumar SV. Multiple myeloma. New Eng J Med. 2004;351:1860-1873.

7. Leleu X, Attal M, Arnulf B, et al. Pomalidomide plus low dose dexamethasone is active and well tolerated in bortezomib and lenalidomide refractory multiple myeloma: IFM 2009-02.

8. National Cancer Institute. Physician Data Query (PDQ). Plasma Cell Neoplasms (Including Multiple Myeloma) Treatment. acceced at www.nci.org.

9. National Comprehensive Cancer Network (NCCN) Clinical Practice Guidelines in Oncology. Multiple myeloma. V.1.2013.

10. Munshi NC, Anderson KC. Plasma cell neoplasms. In: DeVita VT, Hellman S, Rosenberg SA, eds. Cancer: Principles and Practice of Oncology. 9th edition. Philadelphia, PA: Lippincott Williams \& Wilkins;
2011:1997-2032. Palumbo A, Anderson K. Multiple myeloma. N Engl J Med. 2011 Mar 17;364(11):10461060.

11. Raje N, Hideshima T, Anderson KC. Plasma cell tumors. In: Kufe DW, Pollock RE, Weichselbaum RR, Bast RC, Gansler TS, Holland JF, Frei E. Cancer Medicine 6. Hamilton, Ontario: BC Decker; 2003:2219-2244.

12. Rajkumar SV, Dispenzieri A. Multiple myeloma and related disorders. In: Abeloff MD, Armitage JO, Lichter AS, Niederhuber JE. Kastan MB, McKenna WG. Clinical Oncology. Philadelphia, PA. Elsevier: 2008:2323-2340.

13. Sirohi B, Powles R. Multiple Myeloma. Lancet 2004;363:875-887.

14. Smith A, Wisloff F, Samson D. Guidelines on the diagnosis and management of multiple myeloma. $\mathrm{Br} \mathrm{J}$ Haematol. 2005;132:410-452.

15. Kyle RA, Rajkumar SV. Criteria for diagnosis, staging, risk stratification and response assessment of multiple myeloma. Leukemia. 2009;23:3-9.

16. Gahrton G, Tura S, Ljungman P, et al. Prognostic factors in allogeneic bone marrow transplantation for multiple myeloma. J Clin Oncol. 1995;13:1312-1322.

17. Olin RL, Vogl DT, Porter DL, et al. Second auto-SCT is safe and effective salvage therapy for relapsed multiple myeloma. Bone Marrow Transplant. 2009;43:417-422.

18. Singhal S, Mehta J, Desikan R, et al. Antitumor activity of thalidomide in refractory multiple myeloma. N Engl J Med. 1999;341:1565-1571.

19. Glasmacher A, Hahn C, Hoffmann F, et al. A systematic review of phase-II trials of thalidomide monotherapy in patients with relapsed or refractory multiple myeloma. Br J Haematol. 2006;132:584-593.

20. Dimopoulos MA, Zervas K, Kouvatseas G, et al. Thalidomide and dexamethasone combination for refractory multiple myeloma. Ann Oncol. 2001;12:991-995.

21. Raab MS, Podar K, Breitkreutz I, Richardson PG, Anderson KC. Multiple myeloma. Lancet 2009;374 (9686):324-39.

22. Paul M, Walker F, Bear RA. Plasmapheresis therapy in a patient with multiple myeloma. Can Med Assoc J 1982;127(10):956.

23. Matus RE, Leifer CE, MacEwen EG, Hurvitz AI. Prognostic factors for multiple myeloma in the dog. J Am Vet Med Assoc 1986;11(188):1288-92.

24. MacEwan EG, Hurvitz AI. Diagnosis and Management of Monoclonal Gammopathies. Vet Clin North American Small Animal Practice 1977;7:119.

25. Collins CD. Problems monitoring response in multiple myeloma. Cancer Imaging 2005;5 (Spec No A):S11926. doiP10.1102/1470-7330.2005.0033.

26. International Myeloma Working Group. Criteria for the classification of monoclonal gammopathies, multiple myeloma and related disorders: a report of the International Myeloma Working Group. $\mathrm{Br} \mathrm{J}$ Haematol. 2003;121(5):749-57. 
27. Longo, Dan (2012). Harrison's Principles of Internal Medicine 18th Edition. Mc Graw Hill Medical. p. 938. ISBN 978-0-07-174889-6.

28. Hargreaves RM, Lea JR, Griffiths $\mathrm{H}$, et al. Immunological factors and risk of infection in plateau phase myeloma (stable phase). J Clin Pathol. 1995;48(3):260-6.

29. Mitchell, Richard Sheppard; Kumar, Vinay; Abbas, Abul K.; Fausto, Nelson. "Multiple myeloma". Robbins Basic Pathology (8th ed.). Philadelphia: Saunders. p. 455. ISBN 1-4160-2973-7.

30. Durie BGM. Treatment of Myeloma - Are We Making Progress? N Engl J Med. 2008;359(9):964-6.
31. Johnson WJ, Kyle RA, Pineda AA, O'Brien PC, Holley KE. Treatment of renal failure associated with multiple myeloma. Plasmapheresis, hemodialysis, and chemotherapy. Arch Intern Med. 1990;150(4):863-9.

32. Child JA, Morgan GJ, Davies FE, et al. High-dose chemotherapy with hematopoietic stem-cell rescue for multiple myeloma. N Engl J Med 2003;348(19):187583.

33. Avet-Loiseau H, Li C, Magrangeas F, et al. Prognostic significance of copy-number alterations in multiple myeloma. J Clin Oncol. 2009;27:4585-90.

doi:10.5455/2319-2003.ijbcp20131202

Cite this article as: Sagar AV, Divya C, Prathyusha A, Haritha P. A detailed approach on multiple myeloma and its treatment. Int $\mathrm{J}$ Basic Clin Pharmacol 2013;2:671-6. 